\title{
Drivers and assemblies of soil eukaryotic microbes among different soil habitat types in a semi-arid mountain in China
}

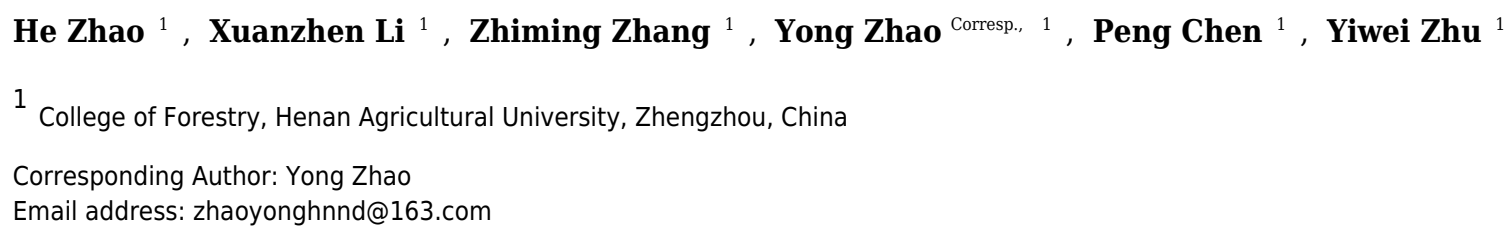

The effects of environmental and species structure on soil eukaryotic microbes inhabiting semi-arid mountains remain unclear. Furthermore, whether community assembly differs in a variety of soil habitat types, e.g., artificial forest, artificial bush, farmland, and natural grassland, is not well understood. Here, we explored species diversity and composition of soil eukaryotic microbes south of the Taihang Mountains (mid-western region of China) using Illumina sequencing of the 18S rRNA gene (V4) region on the MiSeq platform. The results suggest that the forest soil habitat type improved the diversity and abundance of soil eukaryotic microbes that will benefit the restoration of degraded soil. The SAR (Stramenopiles, Alveolates, Rhizaria) supergroup and Metazoa were the dominant soil eukaryotic microbial groups at the phylum level. About $26 \%$ of all operational taxonomic units were common among the different soil habitat types. The O-elements, water content, soil organic matter, and elevation significantly influenced the abundance of soil eukaryote communities $(P<0.05)$. Our findings provide some reference for the effectiveness of local ecological restoration and the establishment of a soil eukaryotic microbe resource databases in a semi-arid area. 
1 Drivers and assemblies of soil eukaryotic microbes among different soil

\section{2 habitat types in a semi-arid mountain in China}

3 He Zhao ${ }^{1 \dagger}$, Xuanzhen $\mathrm{Li}^{1 \dagger}$, Zhiming Zhang ${ }^{1}$, Yong Zhao ${ }^{1 *}$, Peng Chen ${ }^{1}$ and Yiwei Zhu ${ }^{1}$

4 1. College of Forestry, Henan Agricultural University, Zhengzhou, China

5 *Correspondence: zhaoyonghnnd@163.com

6 These authors have contributed equally to this work. 
8 Abstract: The effects of environmental and species structure on soil eukaryotic microbes 9 inhabiting semi-arid mountains remain unclear. Furthermore, whether community assembly 10 differs in a variety of soil habitat types, e.g., artificial forest, artificial bush, farmland, and natural 11 grassland, is not well understood. Here, we explored species diversity and composition of soil 12 eukaryotic microbes south of the Taihang Mountains (mid-western region of China) using 13 Illumina sequencing of the $18 \mathrm{~S}$ rRNA gene (V4) region on the MiSeq platform. The results 14 suggest that the forest soil habitat type improved the diversity and abundance of soil eukaryotic 15 microbes that will benefit the restoration of degraded soil. The SAR (Stramenopiles, Alveolates, 16 Rhizaria) supergroup and Metazoa were the dominant soil eukaryotic microbial groups at the 17 phylum level. About $26 \%$ of all operational taxonomic units were common among the different 18 soil habitat types. The O-elements, water content, soil organic matter, and elevation significantly 19 influenced the abundance of soil eukaryote communities $(p<0.05)$. Our findings provide some 20 reference for the effectiveness of local ecological restoration and the establishment of a soil 21 eukaryotic microbe resource databases in a semi-arid area. 


\section{INTRODUCTION}

Eukaryotic microorganisms comprise most of the natural microbes and they are closely linked with the sustainability of the soil-based ecosystem and biogeochemical processes (Coleman et al., 2004, Falkowski et al., 2008, Delong, 2009). The soil eukaryotic microbial group plays a key role in litter decomposition, nutrient cycling, and soil structural formation (Brussaard et al., 2007). However, the majority of microorganisms are still unknown and cannot be isolated from complex environmental matrices or are not cultivable on microbiological media (Zettler et al., 2002, Rappé et al., 2003, Bonkowski et al., 2004), so they require detailed studies. Particularly, knowledge of the role and dynamics of soil eukaryotic communities in semi-arid areas is rather fragmentary.

Species richness and diffusion capacity are features of eukaryotic microbial communities, which lead them to inhabit a variety of habitat types (Cutler et al., 2013, Luria et al., 2014, Niederberger et al., 2015). Scholars have argued that the abundance of nematode, amoeba, and fungal communities generally increase in aquifer environmental habitats (Madsen et al., 1991, Novarino et al., 2010), and several studies have demonstrated that organic fertilization strongly affects eukaryotic community composition in agricultural habitats (Dong et al., 2014, Lentendu et al., 2014, Murase et al., 2015). Cutler et al. (2013) showed that substrate characteristics affect the abundance/biomass of eukaryotic microbial communities but do not influence diversity in sandstone habitats. Most previous studies only focused on changes in communities of a single habitat type (Michelle et al., 2010, Sonjak, 2005). However, the diversity and composition of eukaryotic microbial communities may differ among various soil habitat types, and comparative analyses of eukaryotic microbial communities are still rare in different semi-arid soil habitats.

Elucidating the composition and diversity of eukaryotic microbial communities is a crucial step for conserving soil productivity and sustainability (Bass \& Cavaliersmith 2004, Staay et al., 2010, Czechowski et al., 2016). Thus, it is necessary to understand the processes responsible for the distribution of eukaryotic microorganisms. Most attempts to identify the structure and coexistence mechanism of natural communities are the joint result of niche theory, which focuses on deterministic processes based on habitat patterns but is restricted by various factors (Tokeshi, 1990, Jongman et al., 1995, Sarah et al., 2016). Niche theory emphasizes that species composition is correlated closely with changes in environmental factors (Leibold, 1995). Some studies have supported niche differentiation and confirmed that abiotic soil factors structure microbial communities (Dumbrell et al., 2010, Lennon et al., 2012). Thus, environmental heterogeneity and spatially structured differences are key factors to explore the distribution of eukaryotic microorganisms. Although ecologists have conducted a series of explorations (Elloumi et al., 2009, Volant et al., 2016), the major environmental drivers of soil eukaryotic microorganism distribution in semi-arid regions remain unclear. 
59

Obtaining detailed and accurate data is key to studies of soil eukaryotic microorganisms. However, traditional soil biodiversity assessments are fundamentally flawed, and the time consumed and taxonomic expertise severely limit the sorting and identification of eukaryotic microbiota (Oehl et al., 2004, Velasco-Castrillón \& Stevens 2014). Thus, new measurement and evaluation methods are constantly being updated. High-throughput sequencing (pyrophosphate sequencing with the Illumina Genome AnalyzerIIx) of soil samples affords an interesting opportunity to confirm microbial genetic variation and classification (Margulies et al., 2006, Chown et al., 2015, Zhao et al., 2017). This technology provides more comprehensive and accurate sequencing data (Opik et al., 2010a) that are beneficial to accurately identify microbes in a variety of vegetation types (Rogers 2007, Marchesi \& Ravel 2015). Applying new technologies provides very useful insight, but more explicit microbiological information in a variety of research areas is still needed.

The area south of the Taihang Mountains in China has a typical semi-arid climate, and soil degradation is common (Zhao, 2007). Vegetation restoration is a traditional practice widely used to prevent ecosystem degradation in this region of China, and many areas have been planted with artificial shrubs and trees (Zhao et al., 2017). Hitherto, most studies of local vegetation restoration have focused on soil physicochemical properties, enzyme activities, root characteristics, and plant growing conditions (Zhang et al., 2006, Pei et al., 2015, Song et al., 2017), but few studies have considered the characteristics of local microorganisms. We hypothesized that the presence of soil eukaryotic microbes is closely related to soil habitat types. To test our hypothesis, we used $18 \mathrm{~S}$ rRNA gene (V4) region to analyze the sequenced data from the Illumina MiSeq platform. The test aimed to: (1) identify the composition and richness of the current soil eukaryotic microorganisms in the area south of the Taihang Mountains; (2) illustrate any differences in soil eukaryotic microbes among soil habitat types, including forest, shrub, grass, and farmland soil habitats; (3) and assess the drivers of environmental factors on soil eukaryotic microorganism assembly in this semi-arid region.

\section{MATERIALS AND METHODS}

\section{Study area}

The area south of the Taihang Mountains (112 $\left.28^{\prime}-112^{\circ} 30^{\prime} \mathrm{E}, 35^{\circ} 01^{\prime}-35^{\circ} 03^{\prime} \mathrm{N}\right)$ is a semi-arid region in China. The study area has a continental monsoon climate in most parts, with an average annual sunshine rate of $54 \%$, average air temperature of $14.3^{\circ} \mathrm{C}$, and annual precipitation of 440 $860 \mathrm{~mm}$. The most common soil is Ustalf (USDA classification). Local vegetation restoration began in 1958. The main land-use methods are grass soil, forest soil, shrub soil, and farmland. Most of the forest soil habitat types are artificial forests, including Platycladus orientalis (L.) Franco, Quercus variabilis B1., and Robinia pseudoacacia L. Lespedeza bicolor Turcz., Vitex 
94 negundo L., and Ziziphus jujuba Mill. var. as the major shrub types. Artemisia princeps H. Lév., 95 Setaria viridis (L.) Beauv., and Arthraxon hispidus (Thunb.) Makino are the dominant 96 herbaceous plants in the natural grass soil. All farmland species were planted by local residents 97 and include Zea mays L., Triticum aestivum L., Ipomoea batatas L., Brassica campestris L., and 98 Lycopersicon esculentum Mill.

\section{Sampling Design}

Based on the status of the local vegetation resources (Zhao, 2007), we established study plots, which represented the ecological systems classified as the forest, shrub, grass, and farmland soil habitat types in October 2017. Samples were collected from the different soil habitat types (each type had three plots), and 12 independent plots $(10 \times 10 \mathrm{~m})$ were set up. Soil samples were collected at a soil depth of $5-10 \mathrm{~cm}$ and were taken along the " $\mathrm{S}$ " model from five sampling points, then pooled together as one large sample for each plot. After cleaning up the impurities, $200 \mathrm{~g}$ soil in the $\mathrm{O}$ horizon was collected at a depth of $0-5 \mathrm{~cm}$. Root samples in the vicinity of the soil samples were also collected with a soil auger (inner diameter $=4 \mathrm{~cm}$ ) at a depth of $5-10$ $\mathrm{cm}$. We carefully collected the soil samples and placed them in freezing boxes for storage at $-70^{\circ} \mathrm{C}$ until further soil geochemical and molecular biological analyses.

\section{Topography, Soil Properties, and Fine Root Data}

Topographic data were taken from each plot of the different soil habitat types. GPS was used to record the longitude, latitude, and elevation of all plots. A clinometer was used to analyze the slope. The parameter settings followed Harms et al. (2001) and Valencia et al. (2004).

The composition of soil organic matter (SOM) was measured by the potassium dichromate volumetric method (Bao, 2000). Water content was measured according to a soil agricultural chemistry analytical method (Bao, 2000). A soil auger were used to collect the $\mathrm{O}$ horizon soil (five samples in a diagonal line for each plot), and the O-elements (O horizon soil elements) were measured by inductively coupled plasma mass spectrometry (Agilent Technologies, Palo Alto, CA, USA). A soil thermograph (TZS-1W; Zhejiang Tuopu Instrument, Zhejiang, China) was used to record the temperature of each soil sample.

Fine root biomass was determined by rinsing the surface of the root samples with clean water. Then, the roots were dried in the shade. Vernier calipers were used to sift out root diameters $>2 \mathrm{~mm}$ in all root samples. The fine roots of each sample were weighed fresh and biomass was determined by the formula (biomass $=$ fine root fresh weight $\times 10^{4} / \pi^{*}$ (inner diameter of earth drill/2) $)^{2}$ ).

\section{Soil DNA Extraction and Miseq Sequencing Step}


127

128

129

130

131

132

133

134

135

136

137

138

139

140

141

142

143

144

145

146

147

148

149

150

151

152

153

154

155

156

157

158

159

160

Soil total DNA was extracted from $50 \mathrm{mg}$ of soil in each plot using the Fast DNA Isolation Kit according to the manufacturer's instructions (Q biogene; Heidelberg, Germany). After checking DNA concentration and purity, the extracted soil DNA was stored at $-20^{\circ} \mathrm{C}$ for further use. The DNA extraction methods for the eukaryotic soil microbes were described by Wu et al. (2011) and Bates et al. (2013).

The V4 region was defined by the primer set forward (5'-CCAGCASCYGCGGTAATTCC$3^{\prime}$ ) and reverse (5'-ACTTTCGTTCTTGATYRA-3') to amplify the sequences (18S rRNA gene fragment). This primer set has been successfully used for eukaryotic microbes in several studies (Bittner et al., 2013, Logares et al., 2014). We used a two-step polymerase chain reaction (PCR) to construct the data library. First, specific primers were used to amplify the target fragment, and the target fragment was recycled with a Gel Recovery Kit (ASJ0013 Gel extraction AxyPrep DNA; Axygen Scientific Inc., Union City, CA, USA). Then, the recovery product was used as the template for the second PCR amplification. The purpose of this method was to add the necessary sequencing joints, barcodes, and sequencing primers to the ends of the segment for sequencing on the Illumina platform. More detailed steps of the two-step PCR are shown in Table S1 and S2. The libraries were sequenced using the PE300 and a MiSeq v3 Reagent Kit (Tiny Gene Co., Shanghai, China).

\section{Bioinformatics Method}

Mothur v. 1.33.3 and UPARSE (version v8.1.1756) software was used to analyze the sequence libraries following the methods of Schloss et al. (2009). The original FASTQ files were denoised and split by the barcode. The portable executable reads for each sample were run in Trimmomatic (version 0.35), using the parameters (maxambig $=0$, length $=200-580$, which protected the longer correct fragments through a higher threshold, maxhomop $=8$ ) and avoided low quality base pairs. Moreover, the sequence data were aggregated with $97 \%$ homology to operational taxonomic units (OTUs) (Edgar, 2013), and the NCBI database was used to blast each OTU representative sequence. The OTUs were also determined based on NCBI (highest score in blast was classified as the matched species, and incorrect OTU information was corrected or removed).

\section{Statistical Procedures}

Statistical analyses of alpha diversity (including OTU richness, Coverage, Chao 1, and Shannon's indices) were performed in Mothur v. 1.33.3 software following Schloss et al (2009). The topography, soil properties, and fine root data were analyzed by one-way analysis of variance using SPSS v. 19.0 software (SPSS Inc., Chicago, IL, USA). The eukaryotic community tree with the four soil habitat types was prepared using MEGA software (version 5.0) (Figure S1). 
161 We used statistical software to analyze the dissimilarity of the dominant soil eukaryotic 162 microbial groups among each soil habitat type, and a Venn diagram of shared OTUs was also 163 prepared using the "VennDiagram" library; the indicator species analysis was prepared using the 164 “indicspecies" library (Ri386 3.4.4). The network was generated with Cytoscape v. 2.8 software 165 (Smoot et al., 2011). A principal component analysis was performed using Ri386. 3.4 .4 (Table 166 S3). Distance-based redundancy analysis (db-RDA) is an efficient method to detect soil 167 eukaryotic microbial group-environmental correlations regarding the response of the soil 168 eukaryotic community to environmental variables. Thus, the Monte Carlo permutation and db169 RDA tests were charted using Ri386. 3.4.4 ("vegan" library), and the graph was optimized using 170 Canoco software (Windows 4.5 package) (Braak \& Smilauer, 2002). All raw sequences have 171 been deposited into the NCBI database under accession number SRP148713. 
172

173

174

175

176

177

178

179

180

181

182

183

184

185

186

187

188

189

190

191

192

193

194

195

196

197

198

199

200

201

202

203

204

205

\section{RESULTS}

\section{Soil eukaryotic microbial data analyses}

We obtained a total of 362,717 sequences and 1,056 OTUs (at 3\% evolutionary distance) from the entire dataset, and the number of OTUs ranged from 396 to 603 per soil sample. The average coverage estimator value was $98.3 \%$ (range, 97.5 - 98.7\%), indicating that the sequence data sufficiently covered the diversity of the eukaryotic population. Based on the Shannon's index analysis, the eukaryotic diversity in the study region ranged from 1.17 to 3.5 (Table 1). Tukey's HSD test was used to evaluate the significance of the results. Eukaryotic richness in the forest soil habitat type was significantly higher than the richness of the farmland, shrub, and grass soil habitat types. The diversity of eukaryotes in the forest and shrub soil habitat types was significantly higher than that in the other habitat types; farmland had the lowest eukaryotic diversity (Table 2). The indicator species analysis revealed soil eukaryotic microbe characteristic $(p<0.05)$ were different among the soil habitat types; a total of 98 indicators were detected in forest soil, rhizarian taxa (35 indicators) had a dominant position; 49 indicators were detected in farmland soil, metazoa taxa (19 indicators) comprised the main group; 74 indicators were found in shrub soil (25 indicators in metazoa taxa), and 48 indicators were observed in grass soil (35 indicators in rhizarian taxa) (Supplementary Table S4). More detailed information about the OTUs in all soil samples is shown in Supplementary Table S5.

\section{Soil eukaryotic microbial composition south of the Taihang Mountains}

The species composition of soil eukaryotic microbes remarkably differed among the different soil habitat types. Fungal (mainly Ascomycota, Basidiomycota, Chytridiomycota, Cryptomycota and Glomeromycota), Cercozoa, Chlorophyta, Amoebozoa, Stramenopiles, Alveolata (mainly Ciliophora, Apicomplexa and Dinophyceae), and Metazoa (mainly Nematoda) were the dominant soil eukaryotic microbial groups. OTUs that could not be identified were assigned as unclassified (Figure 1). Within the soil fungi groups, Cryptomycota occupied the largest component, particularly in farmland (11.3 - 13.1\%). Nematoda and Arthropoda dominated the Metazoa in the study area. Nematoda was extremely abundant among the soil metazoan groups (12.7 - 31.5\%). Eucoccidiorida was comprised mainly of order Apicomplexa sequences. Heterocapsaceae was the main group of the Dinophyceae sequences.

Similarities and differences in the soil eukaryotic microbes among the different soil habitat types.

We applied Venn and network diagrams to reveal the differences in the OTU distributions among the different soil habitat types. The Venn diagrams showed that the number of soil habitat type OTUs ranged from 552 (farmland soil) to 814 (grass soil), and only 270 of 1,056 OTUs 
206 were shared by the four soil habitat types. Moreover, there were 32 shared OTUs in the soil 207 metazoan groups (200 OTUs), 23 shared OTUs in soil fungi (126 OTUs), 30 common OTUs in 208 Alveolata (105 OTUs), and 90 OTUs existed in all of the rhizarian communities (268 OTUs) 209 (Figure 2). Network analyses revealed that the dominant OTUs were different among the four 210 soil habitat types. Forest soil was dominated by OTU_7 (Metazoa), OTU_9 (unclassified), 211 OTU_10 (Alveolata) and OTU_12 (Metazoa). Shrub soil was dominated by OTU_3 (Alveolata), 212 OTU_17 (Metazoa) and OTU_22 (Fungi). Farmland soil was dominated by OTU_31 (Metazoa), 213 whereas grass soil was dominated by OTU_20 (unclassified) (Figure 3). Furthermore, network 214 analyses provided more insight into these shared OTUs (OTUs existed in different land types).

215 The results show that soil habitat types with high species diversity (forest and shrub habitat types) 216 shared larger OTUs (a higher number of sequences) than in the low species diversity habitat 217 types (grass and farmland habitat types). The number of sequences of shared OTUs in the grass 218 type was usually smaller than the others. The OTUs with few sequences $(<200)$ was the main 219 portion of shared OTUs among the four soil types, suggesting that the eukaryotic microbes with few sequences can more easily adapt to different soil habitats (Figure 3).

221

222

223

224

225

226

227

228

229

230

231

\section{Effect of environmental factors on the soil eukaryotic community}

The db-RDA of all soil habitat types and eukaryotic communities mainly showed the variation in the composition of the soil eukaryotic groups, which was explained by soil properties (water content, organic matter, O-elements, and soil temperature,) and partly by plant factors (fine root biomass) and geographical position (elevation and slope) (Figure 4). These environmental factors explained $81.06 \%$ of the variation in the soil eukaryotic community, while $18.94 \%$ of the variation was not explained in the ordination diagram. TOM $1\left(\mathrm{r}^{2}=0.7311, p<0.01\right)$, elevation $\left(\mathrm{r}^{2}=0.6032, p<0.01\right)$, water content $\left(\mathrm{r}^{2}=0.4706, p<0.05\right)$, and SOM $\left(\mathrm{r}^{2}=0.5092, p<0.05\right)$ were the most important factors (Table 3), whereas the effects of soil temperature, slope, and fine root biomass were less influential. 
232

233

234

235

236

237

238

239

240

241

242

243

244

245

246

247

248

249

250

251

252

253

254

255

256

257

258

259

260

261

262

263

264

265

266

\section{DISCUSSION}

Previous studies have reported the soil eukaryotic taxa by molecular techniques at other sites (Bailly et al., 2007, Tzeneva et al., 2009). Our present study fully examined the soil eukaryotic microorganism data across different soil habitat types in the area south of the Taihang Mountains. The results show that the Shannon and chaol indices were significantly different among the different soil habitats $(p<0.05)$; the highest value were in the forest soil habitat type, followed by shrub and farmland. This result may be because forest soil has more substrate diversity leading to species-rich microbes, and human disturbance might reduce the diffusion and growth processes of microbes (Opik et al., 2010b, Jing et al., 2014). Indeed, it is generally accepted that a single cropping system and excessive fertilization are applied to Chinese farmland ecosystems (Xin et al., 2016), so the microbial community structure tends to be less diverse in farmland. The forest and shrub soil habitat types provide sheltered habitat for small animals, and their activities and excreta increase soil nutrient contents to enrich the soil microbe species (Corstanje et al., 2007, Raiesi \& Beheshti, 2015).

Sequencing results have elucidated that the dominant composition of eukaryotic groups among the different soil habitat types was roughly similar. Within the eukaryotic communities, the SAR (Stramenopiles, Alveolates, Rhizaria) supergroup (comprising about $39.76 \%$ of the sequences) was the dominant group at the phylum level, followed by Metazoa (37.78\%). Fungi was another highly represented group (12.82\%). A similar distribution was reported in the Loess Plateau area of northwest China (Jing et al., 2014). Bailly et al. (2007) analyzed the eukaryotic microbes using a metatranscriptomic approach in a coastal sand dune. Those authors assumed that sequence number was closely related to cytoplasmic volume (biologically active), and most protists are single-celled organisms, compared with fungi, with a high copy number per haploid genome (Bailly et al., 2007). Therefore, using ribosomal sequences leads to a far higher ratio of protist to fungal sequences.

Furthermore, contrary to Logares et al. (2014), who confirmed that several microbial taxa are unique to a single location and few are shared among different plots, our results showed that a large number of eukaryotic communities (25.6\% of all OTUs) were shared by the different soil habitat types. These results may have occurred because soils have more complex chemical and physical features than water and the adaptive strategies of eukaryotes in soil differ from those in the aquatic environment (Pommier et al., 2007, Fuhrman et al., 2008). Our results also show that few OTUs existed in one soil habitat type, possibly because certain microbes exist in specific habitats and need a specific climate, nutrients, soil texture, or other factors (Jing et al., 2014, Song et al., 2017). Interestingly, the number of protozoan (Alveolates 29.1\%; Rhizaria 33.6\%) OTUs was larger than the fungal OTUs (18.3\%), suggesting that the protozoa were better 
267

268

269

270

271

272

273

274

275

276

277

278

279

280

281

282

283

284

285

286

287

288

289

290

291

292

293

294

295

296

297

298

299

300

301

adapted to the semi-arid mountain environment than fungi. The network results also indicate that the eukaryotic microbes with different sequences may have different environmental adaptation strategies. However, we studied the distribution of eukaryotic communities only from the habitat angle. Other possible factors, such as spreading ability and the competitive relationships of eukaryotes, were not considered here.

The db-RDA indicated that the variation in species composition of the soil eukaryotic microorganisms was mainly explained by soil properties and geographical factors. Our study assessed the relationship between variations in the soil eukaryotic community and multiple environmental factors in the area south of the Taihang Mountains. The results showed that the composition of soil eukaryotic communities was closely related to water content, SOM, the Oelements, and elevation and the O-elements was the most significantly related $(p<0.05)$. The large number of litters in the $O$ horizon soil indicated greater nutrient cycling and the accumulation of a considerable pool of nutrient elements in soil for use by the microbes (Smolander et al., 2005, Kanerva \& Smolander, 2008). The results also indicated that elevation was the second most influential factor $(p<0.01)$. The effect of elevation on biological distribution was integral to terrestrial ecosystems (Rahbek, 2005, Malhi et al., 2010). The climate change caused by changes in elevation alters the living space of microbial communities, resulting in the close association between microbes and elevation (Smith et al., 2012, Shen et al., 2016).

Furthermore, the water content and SOM also significantly influenced the eukaryotic groups $(p<0.05)$ in this study. Water is an indispensable substance for life and can directly affect reproductive or metabolic processes, and indirectly influence the ecological niches of local microorganism or their physiological status (Skopp et al., 1990, Liu et al., 2010). In addition, Christianl et al. (2008), Antisari et al. (2014) and Ludwig et al. (2014) confirmed that soil SOM is an essential energy source for microbial activities including reproduction. In general, our research considered substrate variables as well as soil properties and environmental factors based on niche theory, but further studies on the relationship between geographic isolation or other factors and eukaryotic groups will be conducted in the future.

\section{CONCLUSIONS}

Elucidating the drivers and assemblages of soil eukaryotic microbes is a critical step to reflecting the trends in recent ecological restoration. Species diversity and composition of soil eukaryotic microbes in the area south of the Taihang Mountains was delineated for the first time in this study. Our results indicate that the soil eukaryotic microbes were closely related to different soil habitat types. The highest eukaryotic richness and diversity were found in the forest soil habitat type; the SAR supergroup and Metazoa were the dominant soil eukaryotic groups, about $26 \%$ of total OTUs were shared in each soil habitat type. Our study also show the relationship between 
302 soil eukaryotic microbes and different environmental factors. The results suggest that the O303 elements, water content, SOM, and elevation were significant driving factors in the soil 304 eukaryotic microorganism communities. There findings confirm that forest soil habitat is an 305 efficient means to restore local vegetation and shed new light on the distribution of local soil 306 eukaryotic microbes in semi-arid areas.

307

308

309

310

311

312

313

314

315

316

317

318

319

320

321

322

323

324

325

326

327

328

329

330

331

332

333

\section{ACKNOWLEDGEMENTS}

All authors thank the Xiaolangdi Ecological Station for the provision of the soil materials and testing ground. And we also thank the Tiny Gene Bio-Tech (Shanghai) Co., Ltd. for their high-throughput sequence technology.

\section{$-$}

\section{REFERENCES}

1. Amaral Zettler LA, Gómez F, Zettler E, Keenan B G, Amils R, and Sogin M L. 2002. Microbiology: eukaryotic diversity in Spain's River of Fire. Nature 417:137.

2. Antisari LV, Marinari S, Dell'Abate MT, Baffi C, and Vianello G. 2011. Plant cover and epipedon SOM stability as factors affecting brown soil profile development and microbial activity. Geoderma 161:212-224.

3. Bailly J, Fraissinet-Tachet L, Verner MC, Debaud JC, Lemaire M, Wésolowski-Louvel M, and Marmeisse R. 2007. Soil eukaryotic functional diversity, a metatranscriptomic approach. Isme Journal 1:632.

4. Bao SD. 2000. Soil agricultural chemical analysis.3 edition. China Agriculture Press (in Chinese).

5. Bass D, and Cavaliersmith T. 2004. Phylum-specific environmental DNA analysis reveals remarkably high global biodiversity of Cercozoa (Protozoa). Int J Syst Evol Microbiol 54:2393-2404.

6. Bates ST, Clemente JC, Flores GE, Walters WA, Parfrey LW, Knight R, and Fierer N. 2013. Global biogeography of highly diverse protistan communities in soil. Isme Journal $7: 652-659$.

7. Bittner L, Dolan JR, Pawlowski J, and Bass D. 2013. The Protist Ribosomal Reference database ( PR2 ): a catalog of unicellular eukaryote Small Sub-Unit rRNA sequences with curated taxonomy The Protist Ribosomal Reference database ( PR 2 ): a catalog of unicellular eukaryote Small Sub-Unit rRNA sequences wi. Nucleic Acids Research 41:D597. 
334

335

336

337

338

339

340

341

342

343

344

345

346

347

348

349

350

351

352

353

354

355

356

357

358

359

360

361

362

363

364

365

8. Bonkowski M. 2004. Protozoa and plant growth: the microbial loop in soil revisited. New Phytologist 162:617-631.

9. Braak T, and Smilauer PN. 2002. Canoco reference manual and CanoDraw for Windows user"s guide: software for canonical community ord. Ithaca $N y$ Usa Www.

10. Brussaard L, Ruiter PCD, and Brown GG. 2007. Soil biodiversity for agricultural sustainability. Agriculture Ecosystems \& Environment 121:233-244.

11. Chen Y, Svenning JC, Wang X, Cao R, Yuan Z, and Ye Y. 2018. Drivers of Macrofungi Community Structure Differ between Soil and Rotten-Wood Substrates in a Temperate Mountain Forest in China. Frontiers in Microbiology 9.

12. Chown SL, Hodgins KA, Griffin PC, Oakeshott JG, Byrne M, and Hoffmann AA. 2015. Biological invasions, climate change and genomics. Evolutionary Applications 8:23-46.

13. Christianl L, Michaels S, Marka B, and Noah F. 2008. The influence of soil properties on the structure of bacterial and fungal communities across land-use types. Soil Biology \& Biochemistry 40:2407-2415.

14. Coleman DC, Crossley DA, and Hendrix PF. 2004. Fundamentals of Soil Ecology (Second Edition).

15. Corstanje R, Reddy KR, Prenger JP, Newman S, and Ogram AV. 2007. Soil microbial eco-physiological response to nutrient enrichment in a sub-tropical wetland. Ecological Indicators 7:277-289.

16. Cutler NA, Oliver AE, Viles HA, Ahmad S, and Whiteley AS. 2013. The characterisation of eukaryotic microbial communities onsandstone buildings in Belfast, UK, using TRFLP and 454 pyrosequencing. International Biodeterioration \& Biodegradation 82:124-133.

17. Czechowski P, Clarke LJ, Breen J, Cooper A, and Stevens MI. 2016. Antarctic eukaryotic soil diversity of the Prince Charles Mountains revealed by high-throughput sequencing. Soil Biology \& Biochemistry 95:112-121.

18. Delong EF. 2009. The microbial ocean from genomes to biomes. Nature 459:200-206.

19. Dong WY, Zhang XY, Dai XQ, Fu XL, Yang FT, Liu XY, Sun XM, Wen XF, and Schaeffer S. 2014. Changes in soil microbial community composition in response to fertilization of paddy soils in subtropical China. Applied Soil Ecology 84:140-147.

20. Drenovsky RE, Vo D, Graham KJ, and Scow KM. 2004. Soil water content and organic carbon availability are major determinants of soil microbial community composition. Microbial Ecology 48:424. 
21. Dumbrell AJ, Nelson M, Helgason T, Dytham C, and Fitter AH. 2010. Relative roles of niche and neutral processes in structuring a soil microbial community. Isme Journal 4:337345.

22. Edgar RC. 2013. UPARSE: highly accurate OTU sequences from microbial amplicon reads. Nature Methods 10:996-998.

23. Elloumi J, Guermazi W, Ayadi H, Bouain A, and Aleya L. 2009. Abundance and biomass of prokaryotic and eukaryotic microorganisms coupled with environmental factors in an arid multi-pond solar saltern (Sfax, Tunisia). Journal of the Marine Biological Association of the United Kingdom 89:243-253.

24. Falkowski PG, Fenchel T, and Delong EF. 2008. The microbial engines that drive Earth's biogeochemical cycles. Science 320:1034-1039.

25. Fuhrman JA, Steele JA, Hewson I, Schwalbach MS, Brown MV, Green JL and Brown JH. 2008. A latitudinal diversity gradient in planktonic marine bacteria. Proceedings of the National Academy of Sciences of the United States of America. 105: 7774-7778.

26. Harms KE, Condit R, Hubbell SP, and Foster RB. 2001. Habitat Associations of Trees and Shrubs in a 50-Ha Neotropical Forest Plot. Journal of Ecology 89:947-959.

27. Jing Z, Cheng J, Jin J, Su J, and Bai Y. 2014. Revegetation as an efficient means of improving the diversity and abundance of soil eukaryotes in the Loess Plateau of China. Ecological Engineering 70:169-174.

28. Jongman RH, Braak CJFT and Tongeren OFRV. 1995. Data analysis in community and landscape ecology. Cambridge University Press, Cambridge.

29. Kanerva S, and Smolander A. 2008. How do coniferous needle tannins influence $C$ and $N$ transformations in birch humus layer? European Journal of Soil Biology 44:1-9.

30. Leibold MA. 1995. The Niche Concept Revisited: Mechanistic Models and Community Context. Ecology 76:1371-1382.

31. Lennon JT, Aanderud ZT, Lehmkuhl BK, and Schoolmaster DR. 2012. Mapping the niche space of soil microorganisms using taxonomy and traits. Ecology 93: 1867-1879.

32. Lentendu G, Wubet T, Chatzinotas A, Wilhelm C, Buscot F, and Schlegel M. 2014. Effects of long-term differential fertilization on eukaryotic microbial communities in an arable soil: a multiple barcoding approach. Molecular Ecology 23:3341-3355. 
396

397

398

399

400

401

402

403

404

405

406

407

408

409

410

411

412

413

414

415

416

417

418

419

420

421

422

423

424

425

426

427

33. Liu Z, Fu B, Zheng X, and Liu G. 2010. Plant biomass, soil water content and soil N:P ratio regulating soil microbial functional diversity in a temperate steppe: A regional scale study. Soil Biology \& Biochemistry 42:445-450.

34. Logares R, Audic S, Bass D, Bittner L, Boutte C, Christen R, Claverie JM, Decelle J, Dolan JR, and Dunthorn M. 2014. Patterns of rare and abundant marine microbial eukaryotes. Current Biology 24:813-821.

35. Ludwig M, Achtenhagen J, Miltner A, Eckhardt KU, Leinweber P, Emmerling C, and Thiele-Bruhn S. 2015. Microbial contribution to SOM quantity and quality in density fractions of temperate arable soils. Soil Biology \& Biochemistry 81:311-322.

36. Luria CM, Ducklow HW, and Amaralzettler LA. 2014. Marine bacterial, archaeal and eukaryotic diversity and community structure on the continental shelf of the western Antarctic Peninsula. Aquatic Microbial Ecology 73:107-121.

37. Madsen EL, Sinclair JL, and Ghiorse WC. 1991. In Situ Biodegradation: Microbiological Patterns in a Contaminated Aquifer. Science 252:830-833.

38. Malhi Y, Silman M, Salinas N, Bush M, Meir P, and Saatchi S. 2010. Introduction: Elevation gradients in the tropics: laboratories for ecosystem ecology and global change research. Global Change Biology 16:3171-3175.

39. Marchesi JR, and Ravel J. 2015. The vocabulary of microbiome research: a proposal. Microbiome 3:31.

40. Margulies M, Egholm M, Altman WE, Attiya S, Bader JS, Bemben LA, Berka J, Braverman MS, Chen YJ, and Chen ZT. 2006. Margulies, M. et al. Genome sequencing in microfabricated high-density picolitre reactors. Nature 437, 376-380. Nature 441:120-120.

41. Michelle A, Falicia G, Brendan PB and Brett AN. 2010. Bacterial, archaeal and eukaryotic diversity of smooth and pustular microbial mat communities in the hypersaline lagoon of shark bay. Geobiology 2010, 7, 82-96.

42. Murase J, Hida A, Ogawa K, Nonoyama T, Yoshikawa N, and Imai K. 2015. Impact of long-term fertilizer treatment on the microeukaryotic community structure of a rice field soil. Soil Biology \& Biochemistry 80:237-243.

43. Niederberger TD, Sohm JA, Gunderson TE, Parker AE, Tirindelli J, Capone DG, Carpenter EJ, and Cary SC. 2015. Microbial community composition of transiently wetted Antarctic Dry Valley soils. Front Microbiol 6:9. 
428

44. Novarino, G.; Warren, A.; Butler, H.; Lambourne, G.; Boxshall, A.; Bateman, J.; Kinner, N.; Harvey, R.H.; Mosse, R.A.; Teltsch, B, 2010. Protistan communities in aquifers: a review. Fems Microbiology Reviews, 20:261-275.

45. Oehl F, Sieverding E, Mäder P, Dubois D, Ineichen K, Boller T, and Wiemken A. 2004. Impact of long-term conventional and organic farming on the diversity of arbuscular mycorrhizal fungi. Oecologia 138:574-583.

46. Opik M, Moora M, Zobel M, Saks U, Wheatley R, Wright F, and Daniell T. $2010 b$. High diversity of arbuscular mycorrhizal fungi in a boreal herb-rich coniferous forest. New Phytologist 179:867-876.

47. Opik M, Vanatoa A, Vanatoa E, Moora M, Davison J, Kalwij JM, Reier U, and Zobel M. 2010a. The online database MaarjAM reveals global and ecosystemic distribution patterns in arbuscular mycorrhizal fungi (Glomeromycota). New Phytologist 188:223-241.

48. Pei B, Zhu LF, Feng ZP, Jiang YM, Yang XT, and Kong YH. 2018. Seasonal Dynamics of Soil Enzyme Activities Under Five Different Ages of Platycladus orientalis Artificial Forest in the Southern Taihang Mountains. Research of Soil and Water Conservation 7: 170175 (in Chinese).

49. Pommier T, Canbäck B, Riemann L, Boström KH, Simu K, Lundberg P, Tunlid A, and Hagström A. 2007. Global patterns of diversity and community structure in marine bacterioplankton. Molecular Ecology 16:867-880.

50. Rahbek C. 2005. The role of spatial scale and the perception of large-scale species-richness patterns. Ecology Letters 8:224-239.

51. Raiesi F, and Beheshti A. 2015. Microbiological indicators of soil quality and degradation following conversion of native forests to continuous croplands. Ecological Indicators 50:173-185.

52. Rappé MS and Giovannoni SJ. 2003. The uncultured microbial majority. Annual Review of Microbiology, 57:369-394.

53. Rogers AD. 2007. Evolution and biodiversity of Antarctic organisms: a molecular perspective. Philos Trans R Soc Lond B Biol Sci 362:2191-2214.

54. Sarah PC, Julien T, Tringe SG, and Philippe C. 2016. H2-saturation of high affinity H2oxidizing bacteria alters the ecological niche of soil microorganisms unevenly among taxonomic groups. Peerj 4:e1782. 
55. Schloss PD, Westcott SL, Ryabin T, Hall JR, Hartmann M, Hollister EB, Lesniewski RA, Oakley BB, Parks DH, and Robinson CJ. 2009. Introducing mothur: open-source, platform-independent, community-supported software for describing and comparing microbial communities. Applied \& Environmental Microbiology 75:7537.

56. Shen C, Liang W, Shi Y, Lin X, Zhang H, Wu X, Xie G, Chain P, Grogan P, and Chu H. 2016. Contrasting elevational diversity patterns between eukaryotic soil microbes and plants. Ecology 95:3190-3202.

57. Skopp J, Jawson MD, and Doran JW. 1990. Steady-state aerobic microbial activity as a function of soil water content. Soil Science Society of America Journal 54:1619-1625.

58. Smith JL, Halvorson JJ, and Jr HB. 2002. Soil properties and microbial activity across a $500 \mathrm{~m}$ elevation gradient in a semi-arid environment. Soil Biology \& Biochemistry 34:17491757.

59. Smolander A, Loponen J, Suominen K, and Kitunen V. 2005. Organic matter characteristics and $\mathrm{C}$ and $\mathrm{N}$ transformations in the humus layer under two tree species, Betula pendula and Picea abies. Soil Biology \& Biochemistry 37:1309-1318.

60. Smoot ME, Ono K, Ruscheinski J, Wang PL, and Ideker T. 2011. Cytoscape 2.8: new features for data integration and network visualization. Bioinformatics 27:431-432.

61. Song GH, Zhao H, Wang QR, and Fan W. 2017. The Relationship between Secondary Forest and Environmental Factors in the Southern Taihang Mountains. Scientific Reports 7.

62. Sonjak S. 2005. Melanized halophilic fungi are eukaryotic members of microbial communities in hypersaline waters of solar salterns : Botanica Marina. Botanica Marina 43:57-79.

63. Staay SYMd, Tzeneva VA, Staay GWMvD, Vos WMd, Smidt H, and Hackstein JHP. 2010. Eukaryotic diversity in historical soil samples. FEMS Microbiology Ecology 57:420428.

64. Tokeshi M. 1990. Niche Apportionment or Random Assortment: Species Abundance Patterns Revisited. Journal of Animal Ecology 59:1129-1146.

65. Tzeneva VA, Salles JF, Naumova N, de Vos WM, Kuikman PJ, Dolfing J, and Smidt H. 2009. Effect of soil sample preservation, compared to the effect of other environmental variables, on bacterial and eukaryotic diversity. Research in Microbiology 160:89-98.

66. Valencia R, Foster RB, Villa G, Condit R, Svenning JC, Hernández C, Romoleroux K, Losos E, Magård E, and Balslev H. 2004. Tree Species Distributions and Local Habitat 
491

492

493

494

495

496

497

498

499

500

501

502

503

504

505

506

507

508

509

510

511

512

513

514

515

516

Variation in the Amazon: Large Forest Plot in Eastern Ecuador. Journal of Ecology 92:214229.

67. Velasco-Castrillón A, and Stevens MI. 2014. Morphological and molecular diversity at a regional scale: A step closer to understanding Antarctic nematode biogeography. Soil Biology \& Biochemistry 70:272-284.

68. Volant A, Héry M, Desoeuvre A, Casiot C, Morin G, Bertin PN, and Bruneel O. 2016. Spatial Distribution of Eukaryotic Communities Using High-Throughput Sequencing Along a Pollution Gradient in the Arsenic-Rich Creek Sediments of Carnoulès Mine, France. Microbial Ecology 72:1-13.

69. Wu T, Ayres E, Bardgett RD, Wall DH, and Garey JR. 2011. Molecular study of worldwide distribution and diversity of soil animals. Proc Natl Acad Sci U S A 108:1772017725 .

70. Xin X, Zhang J, Zhu A, and Zhang C. 2016. Effects of long-term (23 years) mineral fertilizer and compost application on physical properties of fluvo-aquic soil in the North China Plain. Soil \& Tillage Research 156:166-172.

71. Zhang J, Xi Y, and Li J. 2006. The relationships between environment and plant communities in the middle part of Taihang Mountain Range, North China. Community Ecology 7:155-163.

72. Zhao H, Li X, Zhang Z, Zhao Y, Yang J, and Zhu Y. 2017. Species diversity and drivers of arbuscular mycorrhizal fungal communities in a semi-arid mountain in China. Peerj 5:e4155.

73. Zhao Y. 2007. Analysis and evaluation on degraded ecosystem ecological characterizes of vegetation restoration process in the hill areas of the Taihang Moutains. Doctoral dissertation, Henan Agricultural University (in Chinese). 


\section{Figures:}

518 Figure 1. Relative abundances of the dominant soil eukaryotic microbial groups at each of the 12

519 individual sampling locations in the area south of the Taihang Mountains in a semi-arid region of

520 China. Percentage results were classified at the phylum level.

521 Figure 2. Degree of overlap of the eukaryotic operational taxonomic units in the four soil habitat 522 types

523 Figure 3. Network of the dominant 50 operational taxonomic units (OTUs) in the different soil 524 habitat types. Square nodes of different colors represent the soil habitat types, whereas circular 525 nodes represent the OTUs that connect to different soil habitat types through edges (lines). The 526 center color of the circular node represents the specific soil habitat type that had the highest 527 number of sequenced OTUs among the four soil habitat types.

528 Figure 4 Distance-based redundancy (db-RDA) tests used to interpret the correlations between 529 the soil eukaryotic microbes and environmental properties. Colored and black dots represent 530 eukaryotic communities and plots, respectively. Arrows represent environmental factors. The 531 length of an arrow indicates that the correlation is larger or smaller. The diagram was prepared 532 using the most abundant eukaryotic communities. Abbreviations: WC, water content, SOM, soil 533 organic matter, ST, soil temperature, OSE, O-elements, FRB, fine root biomass. 


\section{Figure 1}

Relative abundances of the dominant soil eukaryotic microbial groups at each of the 12 individual sampling locations in the area south of the Taihang Mountains in a semi-arid region of China.

Percentage results were classified at the phylum level.

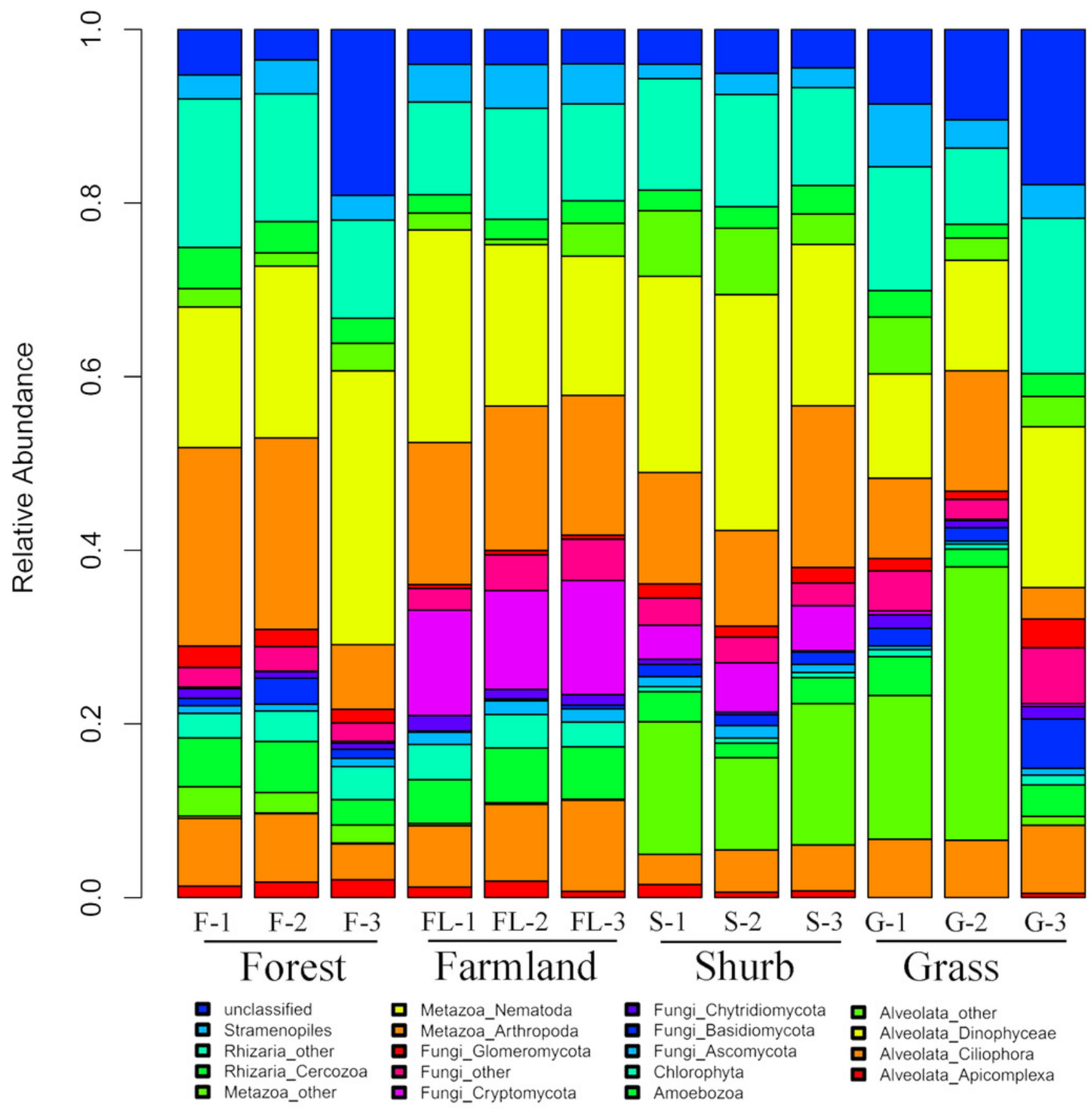


Figure 2

Degree of overlap of the eukaryotic operational taxonomic units in the four soil habitat types
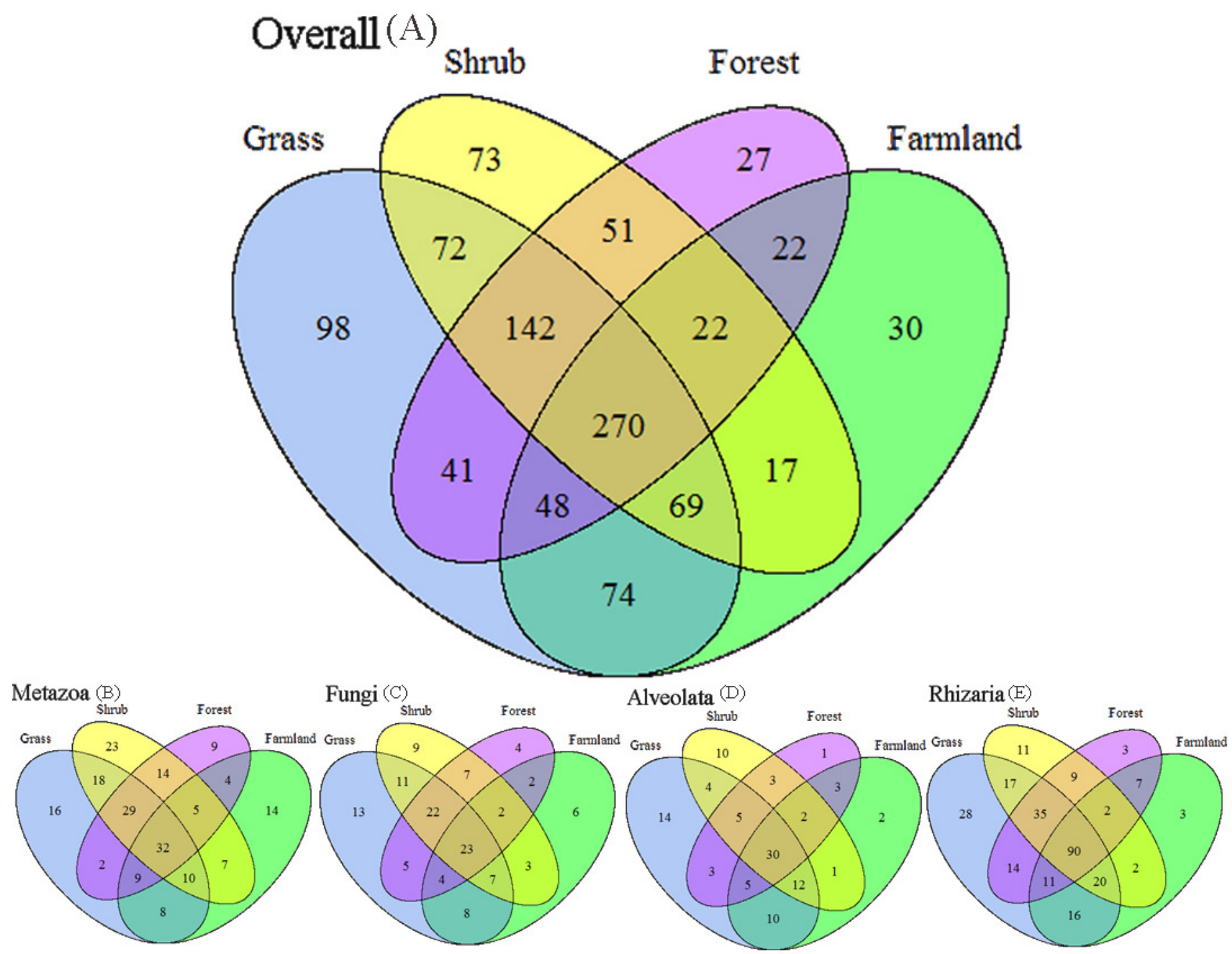
Figure 3

Network of the dominant 50 operational taxonomic units (OTUs) in the different soil habitat types.

Square nodes of different colors represent the soil habitat types, whereas circular nodes represent the OTUs that connect to different soil habitat types through edges (lines). The center color of the circular node represents the specific soil habitat type that had the highest number of sequenced OTUs among the four soil habitat types.

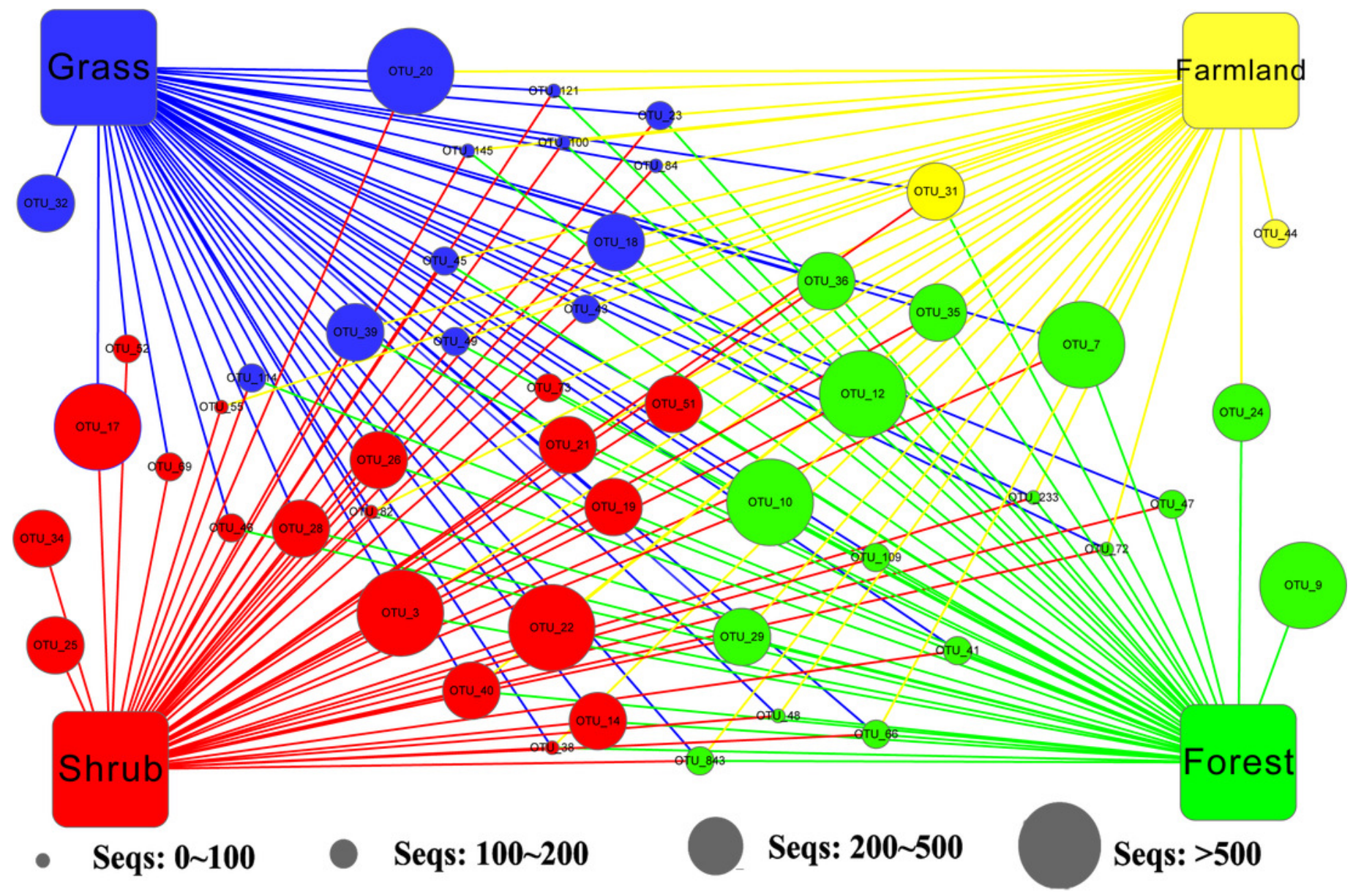




\section{Figure 4}

Distance-based redundancy ( $d b-R D A$ ) tests used to interpret the correlations between the soil eukaryotic microbes and environmental properties.

Colored and black dots represent eukaryotic communities and plots, respectively. Arrows represent environmental factors. The length of an arrow indicates that the correlation is larger or smaller. The diagram was prepared using the most abundant eukaryotic communities. Abbreviations: WC, water content, SOM, soil organic matter, ST, soil temperature, OSE, O-elements, FRB, fine root biomass. 


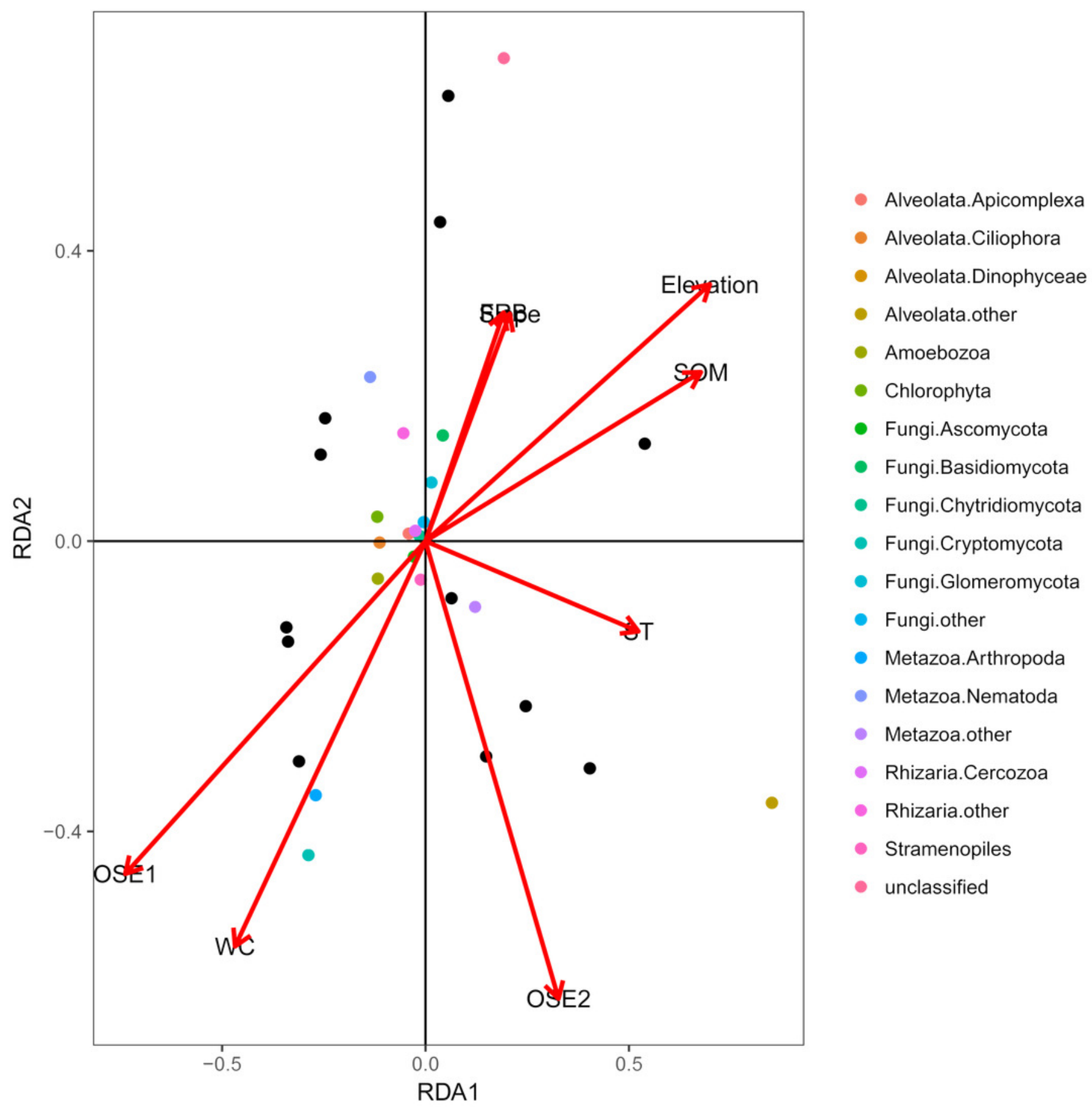




\section{Table $\mathbf{1}$ (on next page)}

Overview of soil eukaryotic microbes, sequence data, environmental factors, and other information. 
1 Table 1 Overview of soil eukaryotic microbes, sequence data, environmental factors, and other 2 information.

\begin{tabular}{cccc}
\hline variables & Minimum & Average value & Maximum \\
\hline Sequences & 19941.00 & $30226.00 \pm 1291.00$ & 35045.00 \\
Number of OTUs & 396.00 & $491.00 \pm 23.00$ & 603.00 \\
Chaol (richness) & 495.17 & $557.74 \pm 17.67$ & 651.43 \\
Soil eukaryote diversity & 1.17 & $2.37 \pm 0.27$ & 3.50 \\
Coverage $(\%)$ & 0.98 & $0.98 \pm 0.002$ & 0.99 \\
Water content $(\%)$ & 15.51 & $22.33 \pm 1.78$ & 32.90 \\
Soil organic matter $\left(\mathrm{g} \mathrm{kg}{ }^{-1}\right)$ & 13.50 & $19.91 \pm 1.15$ & 25.92 \\
Soil temperature $\left({ }^{\circ} \mathrm{C}\right)$ & 12.23 & $13.49 \pm 0.23$ & 14.75 \\
Elevation $(\mathrm{m})$ & 238.26 & $317.88 \pm 12.17$ & 387.88 \\
Slope $\left({ }^{\circ}\right)$ & 0.87 & $9.59 \pm 2.68$ & 31.89 \\
\hline Fine roots biomass $\left(\mathrm{g} \mathrm{m}{ }^{-2}\right)$ & 12.13 & $28.56 \pm 3.41$ & 43.10 \\
\hline
\end{tabular}


Table 2 (on next page)

Geochemical characteristics of the soil samples and other sequence data information in the present study 
1 Table 2. Geochemical characteristics of the soil samples and other sequence data information in the present study.

2 Capital direction symbols (eg. a, b, c) indicate full (5\%) significance.

\begin{tabular}{|c|c|c|c|c|c|c|c|c|c|}
\hline Soil type & chao1 & $\begin{array}{c}\text { Shannon's } \\
\text { index }\end{array}$ & Coverage & $\begin{array}{c}\text { water } \\
\text { content }\end{array}$ & $\mathrm{SOM}$ & Soil temperature & Elevation & Slope & $\begin{array}{c}\text { Fine roots } \\
\text { biomass }\end{array}$ \\
\hline Forest & $643.3 \mathrm{a}$ & $3.21 \mathrm{a}$ & $0.975 \mathrm{~b}$ & $16.3 \mathrm{c}$ & $19.9 \mathrm{ab}$ & $12.9 \mathrm{a}$ & $319 \mathrm{a}$ & $5.6 \mathrm{a}$ & $42.7 \mathrm{a}$ \\
\hline Farmland & $500.7 \mathrm{c}$ & $1.17 \mathrm{c}$ & $0.988 \mathrm{a}$ & $32 \mathrm{a}$ & $14.9 \mathrm{~b}$ & $13.3 \mathrm{a}$ & $284 \mathrm{a}$ & $4.2 \mathrm{a}$ & $12.9 \mathrm{~d}$ \\
\hline Shrub & $563.4 \mathrm{~b}$ & $3.1 \mathrm{a}$ & $0.984 \mathrm{a}$ & $21.1 \mathrm{~b}$ & $22.5 \mathrm{a}$ & $13.9 \mathrm{a}$ & $312 \mathrm{a}$ & $16.7 \mathrm{a}$ & $35 \mathrm{~b}$ \\
\hline Grass & $523.5 \mathrm{bc}$ & $2.0 \mathrm{~b}$ & $0.987 \mathrm{a}$ & $19.9 \mathrm{~b}$ & $22.4 \mathrm{~b}$ & $13.8 \mathrm{a}$ & $356 \mathrm{a}$ & $11.9 \mathrm{a}$ & $23.6 \mathrm{c}$ \\
\hline
\end{tabular}




\section{Table 3(on next page)}

Monte Carlo permutation test to detect the relationship between the eukaryotic communities and the environmental properties.

The variable abbreviations are the same as in Figure $3 . * \mathrm{P}<0.05 ; * \mathrm{P}<0.01$. 
1 Table 3. Monte Carlo permutation test to detect the relationship between the eukaryotic 2 communities and the environmental properties. The variable abbreviations are the same as in 3 Figure $3 . * \mathrm{P}<0.05 ; * * \mathrm{P}<0.01$.

\begin{tabular}{ccccc}
\hline Variables & RDA1 & RDA2 & $\mathrm{R}^{2}$ & P-value \\
\hline WC & -0.76896 & -0.63929 & 0.4706 & $0.046^{*}$ \\
SOM & 0.95132 & 0.3082 & 0.5092 & $0.041 *$ \\
ST & 0.99743 & -0.07172 & 0.2638 & 0.274 \\
Elevation & 0.91968 & 0.39266 & 0.6032 & $0.009 * *$ \\
Slope & 0.70586 & 0.70835 & 0.1198 & 0.582 \\
FRB & 0.6832 & 0.73023 & 0.1139 & 0.577 \\
O-elements 1 & -0.89505 & -0.44597 & 0.7311 & $0.002 * *$ \\
O-elements 2 & 0.54795 & -0.83651 & 0.3337 & 0.124 \\
\hline
\end{tabular}

4 